\title{
Anti-NMDA receptor encephalitis and overlapping demyelinating disorder in a 20-year old female with borderline personality disorder: proposal of a diagnostic and therapeutic algorithm for autoimmune encephalitis in psychiatric patients "case report"
}

David Weiss ${ }^{1,2^{*}} \mathbb{D}$, Lisa Kertzscher ${ }^{1}$, Magdalena Degering ${ }^{1}$, David Wozniak ${ }^{1}$ and Michael Kluge ${ }^{1}$

\begin{abstract}
Background: Anti-NMDA receptor encephalitis (NMDAR-E) is an autoimmune encephalitis (AE) mainly affecting young females. It typically presents with isolated psychiatric symptoms (e.g. depressed mood) at first and neurological abnormalities (e.g. seizures, movement disorders) only develop later. Thus, there is a high risk of overlooking NMDAR-E in patients with preexisting psychiatric illness due to symptom overlap in the prodromal period of the disease when treatment is most effective. Although rare, concomitant or sequential development of a demyelinating disorder is increasingly recognized as an associated disease entity (overlap syndrome), with immediate diagnostic and therapeutic implications.

Case presentation: We report a patient with a borderline personality disorder (BPD), which developed NMDAR-E and an overlapping demyelinating disorder with anti-Myelin oligodendrocyte glycoprotein (MOG) -lgG positivity. The initial clinical presentation with predominantly affective symptoms (e.g. mood lability, anxiety, depressed mood) lead us to suspect an exacerbation of the BPD at first. However, acute changes in premorbid behavior, newly developed psychotic symptoms and memory deficits lead us to the correct diagnosis of an $A E$, which was further complicated by the development of a demyelinating disorder. As a result of impaired illness awareness and psychosis, diagnostic and treatment was difficult to carry out. The symptoms completely remitted after treatment with methylprednisolone $1 \mathrm{~g}$ daily for 5 days and 5 cycles of plasma exchange.
\end{abstract}

\footnotetext{
* Correspondence: David.Weiss@med.uni-rostock.de

'Department of Psychiatry and Psychotherapy, University of Leipzig, Leipzig,

Germany

${ }^{2}$ Department of Neurology, Rostock University Medical Center, Germany;

Gehlsheimer Straße 20, 18147 Rostock, Germany
}

(c) The Author(s). 2021, corrected publication 2021. Open Access This article is licensed under a Creative Commons Attribution 4.0 International License, which permits use, sharing, adaptation, distribution and reproduction in any medium or format, as long as you give appropriate credit to the original author(s) and the source, provide a link to the Creative Commons licence, and indicate if changes were made. The images or other third party material in this article are included in the article's Creative Commons licence, unless indicated otherwise in a credit line to the material. If material is not included in the article's Creative Commons licence and your intended use is not permitted by statutory regulation or exceeds the permitted use, you will need to obtain permission directly from the copyright holder. To view a copy of this licence, visit http://creativecommons.org/ licenses/by/4.0/. The Creative Commons Public Domain Dedication waiver (http://creativecommons.org/publicdomain/zero/1. 0/) applies to the data made available in this article, unless otherwise stated in a credit line to the data. 
Conclusions: Continuous awareness for neuropsychiatric clinical warning signs in patients with a pre-diagnosed psychiatric disorder is important for a timely diagnosis. Therefore, we believe that the diagnostic and therapeutic algorithm provided here, for the first time specifically addressing patients with preexisting psychiatric illness and integrating overlap syndromes, can be a useful tool. Moreover, in order to timely perform diagnostics and treatment, judicial approval should be obtained rapidly.

Keywords: Anti-NMDA receptor encephalitis, Neuropsychiatric red flags, Demyelinating overlap syndrome, Diagnostic and therapeutic algorithm, Case report

\section{Background}

Anti-NMDAR receptor encephalitis (NMDAR-E) is a well-defined immune-mediated disease, based on the presence of antibodies against the NR1 subunit of the $\mathrm{N}$-methyl-D-aspartate (NMDA) receptor [1]. Clinically, NMDAR-E is characterized by a multistage progression of symptoms: prodromal symptoms (e.g. headache, mood changes), psychotic features (e.g. delusions), cognitive decline (e.g. working memory), epileptic seizures, movement disorders (e.g. dyskinesias, dystonic body posture), autonomous instability and reduced consciousness [2]. Diagnosis can be difficult in patients with preexisting psychiatric illnesses due to symptom overlap in the prodromal period, when differentiating neurological symptoms are still lacking [3]. NMDAR-E can coexist with an overlapping demyelinating syndrome, including Myelin oligodendrocyte glycoprotein (MOG) antibody disease [4], implicating the need for additional diagnostics and different therapeutic approaches [5].

\section{Case presentation}

Ms. A. is a 21-year old woman with a 9-year history of borderline personality disorder (BPD) symptoms, with BPD being diagnosed aged 19 when being treated for this reason for the first time. BPD was characterized by experience of emptiness, self-harming behavior (cutting), including three suicide attempts aged 15 and 16, and abuse of illicit drugs, including amphetamines, cannabis and LSD. The father was described as "aggressive", but had no formal psychiatric diagnosis or treatment. Otherwise, the family history and the further patient's history were unremarkable. On admission, BPD was reasonably well controlled, with no hospitalizations or self-harming behavior in the 12 months before admission, a stable partnership, an apprenticeship and a reduced drug abuse limited to sporadic cannabis consumption. Ms. A. occasionally took over-the-counter hypnotics (e.g. valerian), but no other psychotropic medication.

Two weeks before admission, Ms. A. developed persistent headache. On admission, the patient presented with poor attention, anxiety and depressed mood. One week prior to admission, her school was shut down due to the coronavirus pandemic, causing her a lot of distress and fear for the future. In a text message to her father she wrote: "I have no idea how things will develop; I am afraid of getting a nervous breakdown". The day after, she showed signs of confusion for the first time, while still being rational: "I am losing it, everything feels weird, I should see a physician". On the same day she experienced a "nervous breakdown" during her work in a hardware store. Three days later, she was emergently admitted to our clinic, showing mood lability, anxiety and depressed mood. These symptoms were initially interpreted as stress-related exacerbation of the BPD. Neurological and physical examinations were unremarkable.

One week after admission, the patient's cognitive functions deteriorated markedly, with concentration loss, deficits in working memory and disorientation. The Montreal Cognitive Assessment (MoCA) [6] sum score was 18/30, showing significant deficits in delayed recall, abstraction, serial subtraction, verbal fluency and visuospatialexecutive functions. The clock-drawing test was grossly inaccurate (Fig. 1a). In addition, the patient developed psychotic symptoms with paranoid suspiciousness and distrust of others, claiming that the ward staff was made up of "actors", and bizarre thoughts, like asking why she was born. Therefore, olanzapine $20 \mathrm{mg}$ daily was started, which was well tolerated, but had no significant effect. Furthermore, Ms. A. reported having recurring night terrors and suicidal thoughts. The neurological and physical examinations remained unremarkable.

Given the subacute onset, the patient's young age, gender and psychopathology with a newly developed mixed mood-psychosis syndrome [7] and headache, we considered an organic cause, such as AE. Therefore, we planned to perform a diagnostic work-up, including brain MRI, EEG, serum screening for autoantibodies associated with $\mathrm{AE}$ and lumbar puncture. However, Ms. A. refused all diagnostics and treatment except for blood drawing, having anosognosia with poor insight into the presence and nature of the illness. When being confronted with her poor performance in the clock-drawing test, she replied: "I have been this way for all my life, I have never been able to draw a clock; what is this all about, I want to leave the hospital".

In line with our hypothesis, we found elevated NMDA R-antibodies (antibody-titer 1:32) in the serum, indicating an NMDAR-E. Also, the antibody-titer of previously 


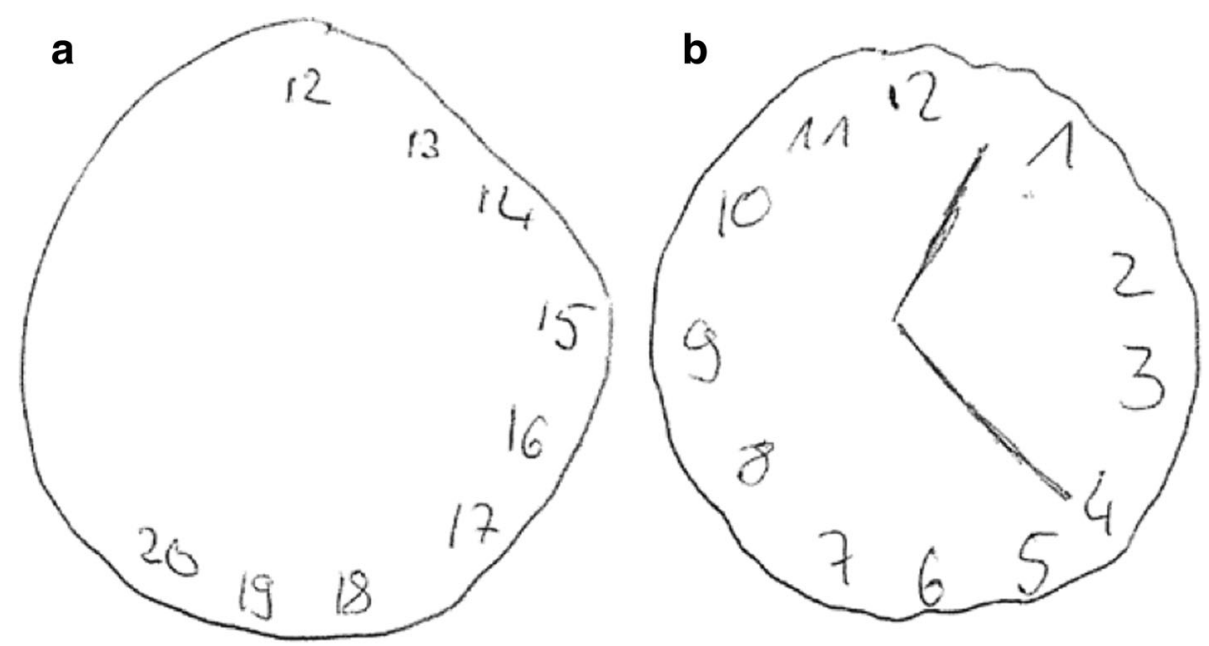

Fig. 1 a Initial clock-drawing test before therapy. b Clock-drawing test at the day of discharge

normal antinuclear antibodies (ANA) was elevated (1: 160), indicative of a newly developed systemic autoimmune disease. Stressing the severity of the illness and its usually harmful course, we successfully applied for an involuntary treatment with coercive disease-specific diagnostics and treatment.

The brain MRI was only feasible under anesthesia. Upon first evaluation, the MRI was considered unremarkable, especially without pathological findings suggestive of an $\mathrm{AE}$, like abnormal signals in the mesial temporal lobes or white matter lesions. The EEG displayed diffuse theta and delta slowing (Fig. 2). The cerebrospinal fluid (CSF) showed several abnormal findings: a monocytic pleocytosis (122 cells per mm3), CSFspecific oligoclonal bands (OCB, Type 2), indicating intrathecal immunoglobulin (antibody) production, and increased CSF/serum antibody indices for rubella and varicella zoster virus (incomplete MRZ reaction). CSF concentrations of protein, lactate and glucose were normal. The rather high CSF pleocytosis - usually autoimmune encephalitis is accompanied by mild pleocytosis from 5 to 100 per $\mathrm{mm} 3$ [2]- prompted us to consider infectious causes (especially a preceding or concurrent herpes simplex encephalitis (HSV), being a well-known trigger for NMDAR-E [8]). Since especially HSV encephalitis, but also bacterial meningoencephalitis, can take an aggressive course, we immediately started treatment with acyclovir, cefotaxime and ampicillin. After the CSF PCR (polymerase chain reaction) test results for Herpesviridae (HSV 1, VZV, CMV, EBV, FSME, HIV, JCV, SARS$\mathrm{CoV}-2$ ), bacterial and fungal etiologies came back negative the next day, we started intravenous immunosuppressive therapy with methylprednisolone1g daily for 5 days. NMDA antibody titer in the CSF was 1:10, confirming the diagnosis of NMDAR-E.
As a result, cognitive performance improved, and psychotic symptoms partly remitted within 5 days. However, neuropsychological testing still demonstrated significant memory deficits and thinking was still disorganized. Moreover, Ms. A. experienced 2 presyncope's and developed sinus tachycardia (up to $150 \mathrm{bpm}$ ), suggestive of autonomic instability, which is a common feature of NMDAR-E [4]. Then, 3 days after discontinuation of high dose glucocorticoid therapy, Ms. A. experienced transient blurred vision on both eyes and unsteady gait. Hence, the brain MRI was re-evaluated for demyelination signs. In fact, an enhancing demyelinating Multiple sclerosis (MS)-like lesion now was detected in the dorsal column of the cervical spinal cord C2/C3 (Figs. 3 and 4). Assuming a newly acquired demyelinating disorder with optic nerve involvement and afferent gait disturbance, we tested for MOG-IgG and Aquaporin 4 (AQP4) antibodies in serum and CSF, being both relevant mediators in autoimmune demyelinating syndromes of the CNS [9]. MOG-IgG antibodies came back positive (antibody titer 1:10) in serum, but not in the CSF; AQP4 antibodies were negative, both in serum and CSF.

Because of the insufficient response to glucocorticoid treatment, the therapy was escalated: Ms. A. underwent 5 cycles of plasma exchange, while oral prednisone 60 $\mathrm{mg}$ daily was continued. Already after the first cycle, cognitive capabilities improved, especially working memory capacity and visuospatial-executive functions. The MoCA sum score improved to 25/30. Also, the clock drawing test substantially improved (Fig. 1b). Blurred vision and unsteady gait remitted. Correspondingly, a control MRI showed disappearance of the previously enhancing demyelinating lesion in the cervical spinal cord. In addition, we performed evoked potentials (VEP, 


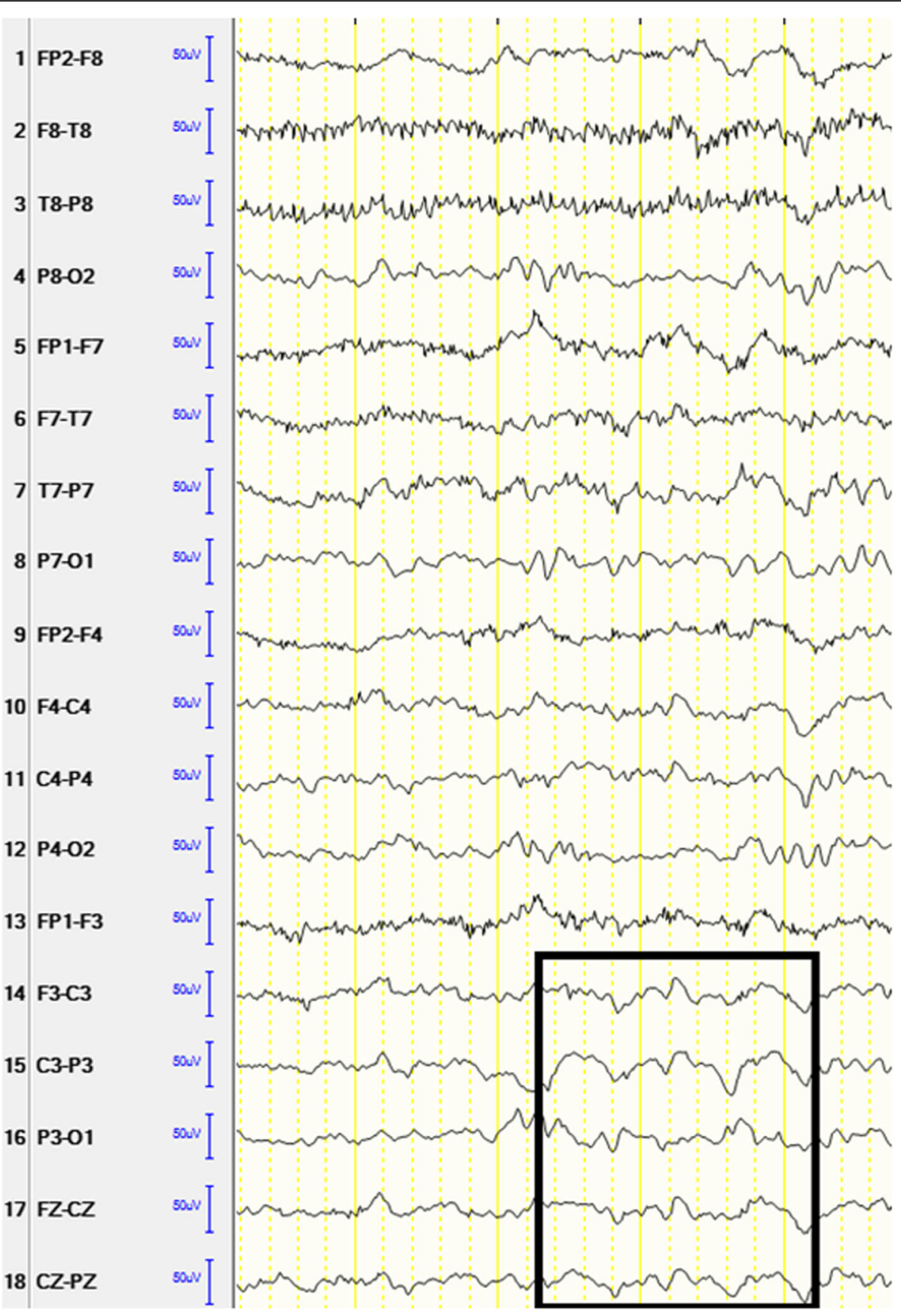

Fig. 2 EEG showing diffuse theta and delta slowing

MEP, SEP) that were unremarkable (no significant differences in latency and amplitude).

In the meantime, an ovarian teratoma, being a paraneoplastic cause for NMDAR-E in approximately $50 \%$ of female patients [10], had been ruled out by pelvic MRI. Other occult malignancies were ruled out by whole body PET/CT. Ms. A. was discharged substantially improved, with only subtle cognitive impairments, which fully remitted upon neuropsychological re-evaluation 4 weeks later. Antipsychotic medication with olanzapine $10 \mathrm{mg}$ daily and immunosuppressive therapy with prednisone $60 \mathrm{mg}$ daily (with a tapering schedule) was continued, since patients with anti-NMDA receptor encephalitis are at risk for relapse [5]. Follow-up neuropsychological testing and monitoring of therapy adherence is ensured by our outpatient clinic. 


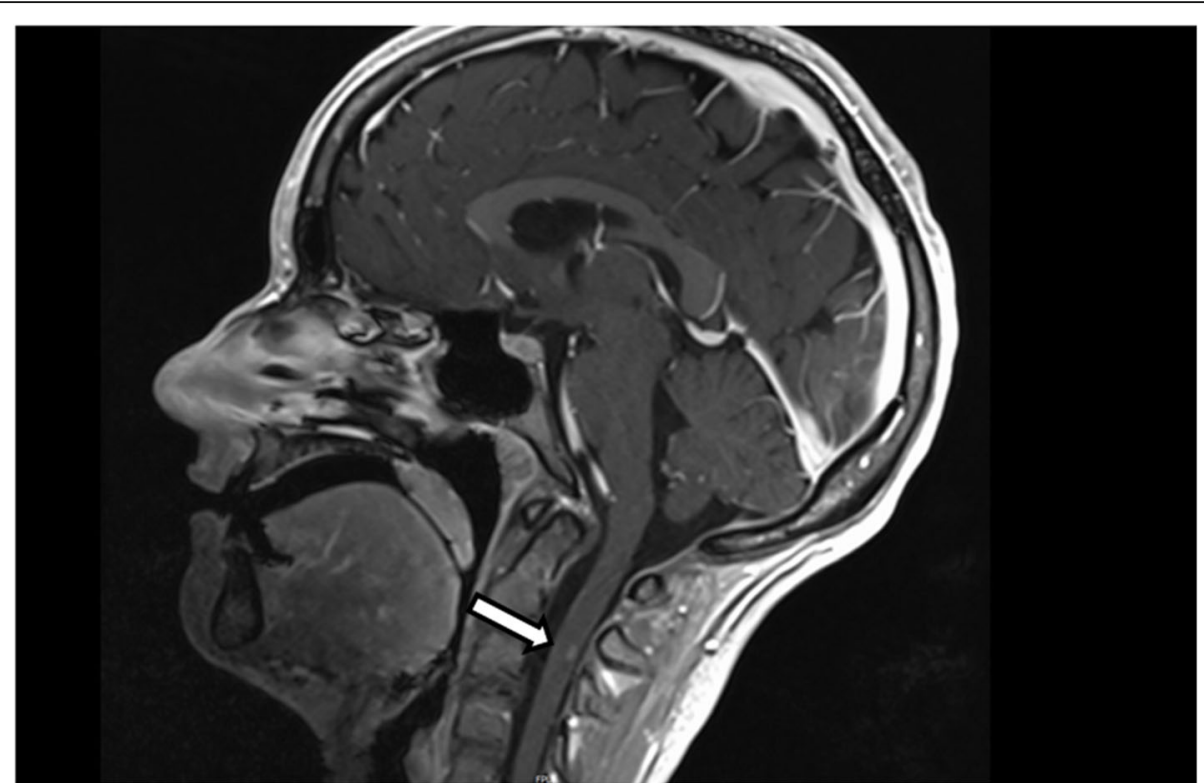

Fig. $3 \mathrm{~T} 1$ weighted image (sagittal), showing contrast enhancement of the lesion in the dorsal column of the cervical spinal cord C2/C3

\section{Discussion and conclusions}

Herein we report a patient with a preexisting BPD, which developed NMDAR-E and an overlapping demyelinating disorder. There are several important conclusions to draw from this case:

Firstly, diagnosing AE in already psychiatrically ill patients is difficult. A high level of alertness is needed, particularly for early diagnosis, when differentiating neurological features are still lacking. Thus, we suggest considering the psychiatric red flags in our proposed algorithm (Fig. 5) as a guide for earlier diagnosis. The difficulty arises primarily because symptoms of autoimmune encephalitis may mimic symptoms of the preexisting psychiatric condition on the one hand, and because a further cause for psychiatric symptoms is simply not being expected, on the other hand [2].. As a result, an autoimmune encephalitis can be easily overlooked, at least at the beginning [16]. In our case, the patient's initial symptoms, mostly affecting mood, were interpreted as an exacerbation of her preexisting BPD.

Secondly, in patients with symptoms atypical for $\mathrm{AE}$ (e.g. paresis), demyelinating disorders should be considered (Fig. 5). Demyelinating disorders such as anti-MOG disease (MOG-AD), can develop concomitantly or sequentially in individuals with NMDAR-E [4, 17]. Likewise, patients with a history of demyelinating disorder

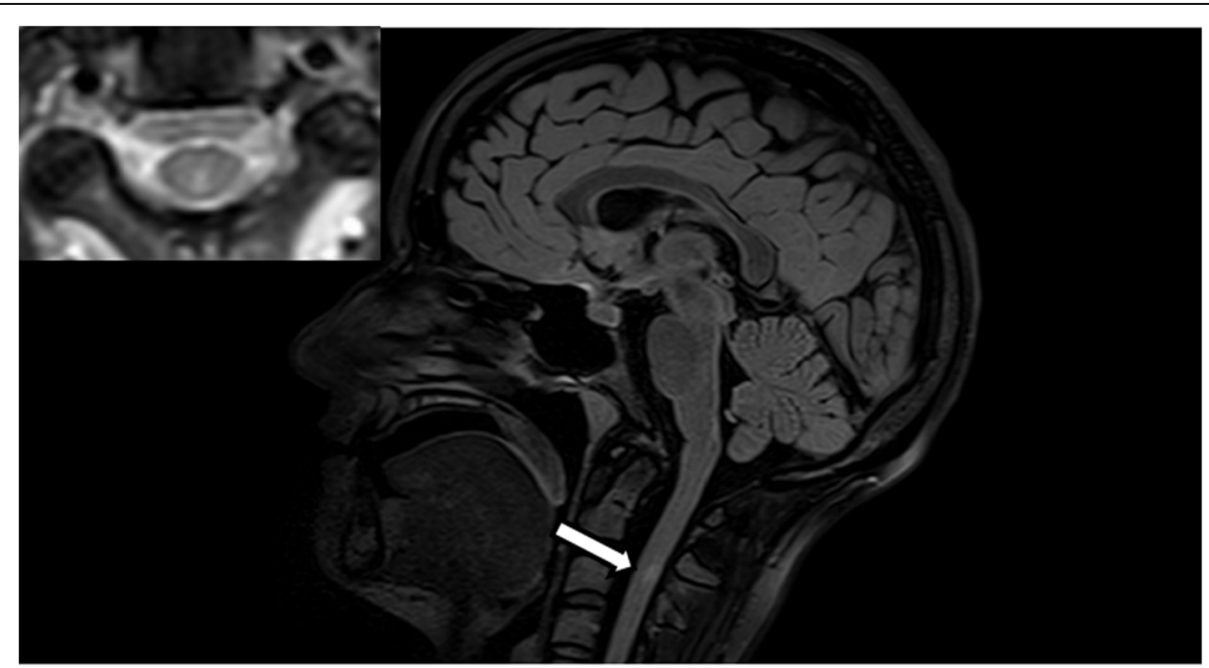

Fig. $4 \mathrm{MRI}$ image (FLAIR sagittal and T2 transversal plane), showing the lesion in the dorsal column of the cervical spinal cord C2/C3 


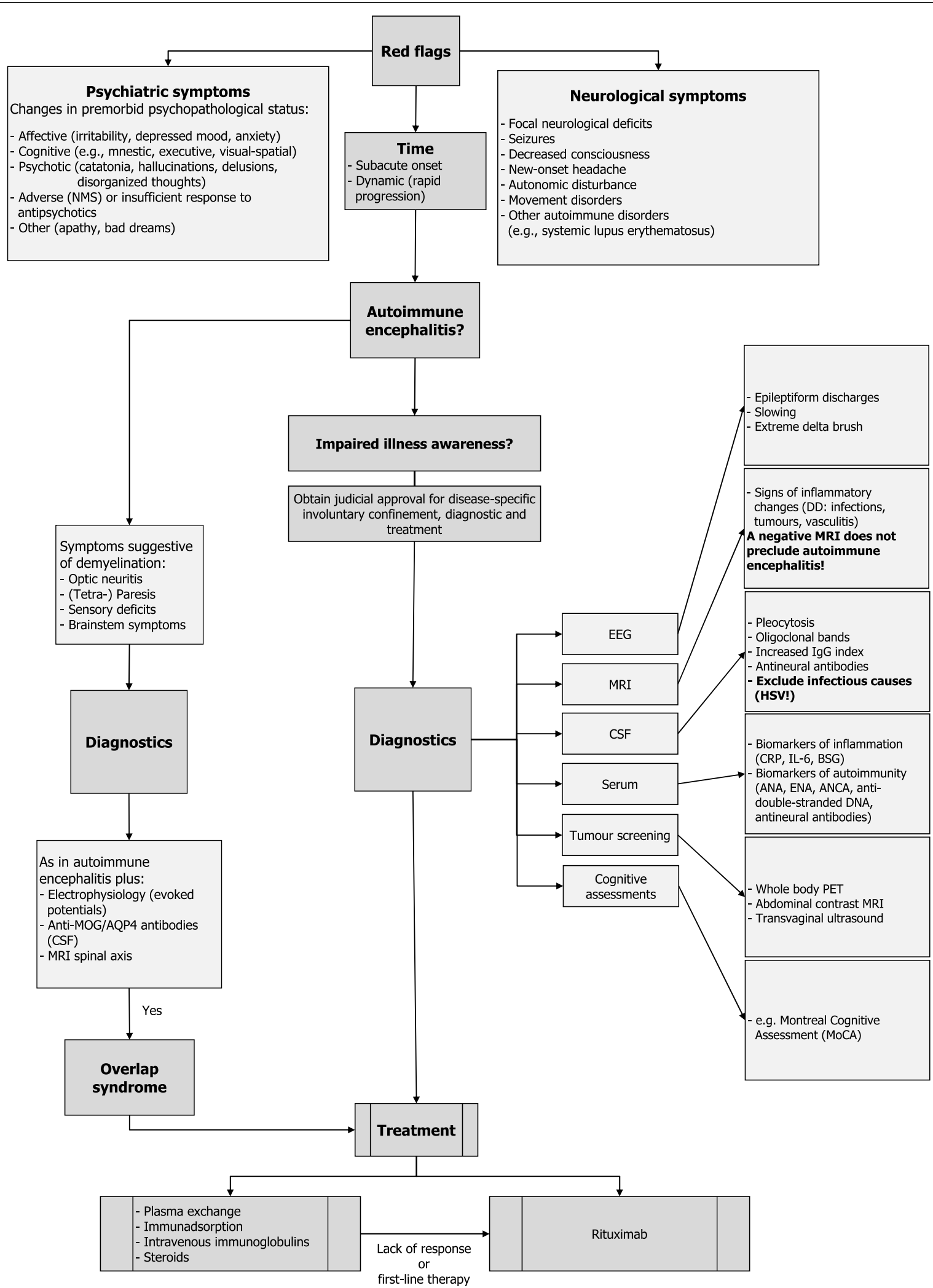

Fig. 5 Diagnostic and therapeutic algorithm, specifically considering patients with preexisting psychiatric illness and integrating overlap syndrome (based on $[2,4,7,8,11-15]$ 
should be tested for co-existing NMDAR-E, if presenting with atypical symptoms such as psychosis or seizures [17]. Although MOG-IgG antibodies were tested positive in our patients serum, some caution should be exerted in diagnosing MOG-AD [18], since the CSF profile of our patient is more suggestive of an MS-like immune response, possibly elicited by NMDAR antibodies: positive MRZ reaction, positive OCBs, preserved blood-CSF barrier integrity and normal CSF albumin concentration [19]. Since oligodendrocytes contain NMDAR, a direct immuno-pathophysiological demyelinating effect of NMDAR-antibodies is conceivable [4]; thus MOG antibodies may rather represent a bystander effect or epiphenomenon in our case. Since the criterion of dissemination in space for diagnosing MS isn't fulfilled and given the absence of any history or clinical signs of MS before the onset of encephalitis, pre-existing MS and now superimposed NMDAR-E seems to be unlikely. Longitudinal reevaluation in this regard however is important, since there are rare case reports of co-existent MS and NMDAR-E [20, 21]. Of note, the unremarkable evoked potentials were performed after having administered 2 cycles of plasma exchange, at a time when the patients' symptoms already had remitted.

Thirdly, as a result of the impaired illness awareness and often psychosis, patients with $\mathrm{AE}$ are frequently unable to consent and commonly refuse diagnostics, significantly delaying urgent treatment. Hence, it is very important to rapidly obtain judicial approval for involuntary confinement, diagnostics and treatment, ultimately to restore the patient's autonomy. Since diagnostics and treatment of $\mathrm{AE}$ is invasive (e.g. lumbar puncture, plasma exchange), explicit approval for disease-specific diagnostics and treatment should be obtained [22].

$\mathrm{AE}$ is a comparatively new disease entity [16]. Therefore, randomized controlled trials are still lacking and thus treatment approaches are largely based on considerable clinical experience [23]. While there are already profound algorithms for diagnostics and treatment of $\mathrm{AE}[5,8,11,22,23]$, we believe that the algorithm provided here, specifically addressing patients with preexisting psychiatric illness and integrating overlap syndrome, can be an additional useful tool for a timely diagnosis and rational treatment. Although methylprednisolone, plasma exchange and intravenous immunoglobulin are considered as first-line therapy, we, in line with others $[5,23]$, propose B-cell depletion with rituximab as firstline and maintenance therapy, since it is associated with fewer relapses and better outcomes [23, 24]. Especially patients with a demyelinating overlap syndrome (and MOG antibody positivity) could benefit, given the shared antibody-mediated immunopathology. In our case, insurance coverage for rituximab as first-line and maintenance therapy (off-label use) was denied. However, rituximab (typically given every 6 months) seems to be especially advantageous as maintenance therapy in psychiatric patients, since lack of adherence is frequent in psychiatric patients [25].

In conclusion, the complex case presented here describes different diagnostic and therapeutic problems encountered with AE, specifically NMDAR-E, and aims at providing specific proposals, based on comprehensive literature review, for their solution. However more clinical experience and long-term reevaluation is needed.

\section{Abbreviations}

AE: Autoimmune encephalitis; ANA: Antinuclear antibodies; AQP4: Aquaporin 4; BPD: Borderline personality disorder; CMV: Cytomegalovirus;

CSF: Cerebrospinal fluid; EBV: Epstein-Barr virus; EEG: Electroencephalogram; FSME: Tick-borne encephalitis virus infections; HIV: Human immunodeficiency virus; HSV: Herpes simplex virus; JCV: John Cunningham virus; MEP: Motor evoked potentials; MOG-AD: Anti-MOG disease; MOG: Myelin oligodendrocyte glycoprotein; MoCA: Montreal Cognitive Assessment; MRI: Magnetic resonance imaging; MS: Multiple sclerosis; NMDAR-E: AntiNMDA receptor encephalitis; NMDA: N-methyl-D-aspartate; OCB: Oligoclonal bands; SARS-CoV-2: Severe acute respiratory syndrome coronavirus 2; SEP: Somatosensory evoked potential; VEP: Visual evoked potentials; VZV: Varicella zoster virus

\section{Acknowledgements}

We acknowledge support from Leipzig University for Open Access Publishing.

\section{Authors' contributions \\ DW and MK treated the patient, did the literature research, drafted the manuscript and developed the provided algorithm. DW participated in the treatment. LK and MD did the neuropsychological testing. LK contributed to the algorithm. All authors critically read, edited and approved the manuscript. \\ Funding \\ Open Access funding enabled and organized by Projekt DEAL. \\ Availability of data and materials \\ All data and material supporting our findings are contained within the manuscript.}

\section{Declarations}

Ethics approval and consent to participate

As this is a case report describing clinical observations, ethic approval was waived.

\section{Consent for publication}

The patient agreed and provided written informed consent for publication of this report. An overseeing mental health expert has ruled that the patient has been deemed ethically and medically capable of consenting for their participation in this report.

\section{Competing interests}

The authors declare that they have no competing interests.

Received: 27 May 2020 Accepted: 9 May 2021

Published online: 15 July 2021

References

1. Prüss H, Dalmau J, Harms L, Höltje M, Ahnert-Hilger G, Borowski K, et al. Retrospective analysis of NMDA receptor antibodies in encephalitis of unknown origin. Neurology. 2010;75(19):1735-9. https://doi.org/10.1212/ WNL.0b013e3181fc2a06.

2. Endres D, Leypoldt F, Bechter K, Hasan A, Steiner J, Domschke K, et al. Autoimmune encephalitis as a differential diagnosis of schizophreniform psychosis: clinical symptomatology, pathophysiology, diagnostic approach, 
and therapeutic considerations. Eur Arch Psychiatry Clin Neurosci. 2020; 270(7):803-18. https://doi.org/10.1007/s00406-020-01113-2.

3. Endres D, Rauer S, Kern W, Venhoff N, Maier SJ, Runge K, et al. Psychiatric presentation of anti-NMDA receptor encephalitis. Front Neurol. 2019;10: 1086. https://doi.org/10.3389/fneur.2019.01086.

4. Titulaer MJ, Höftberger R, lizuka T, Leypoldt F, McCracken L, Cellucci T, et al. Overlapping demyelinating syndromes and anti-N-methyl-D-aspartate receptor encephalitis. Ann Neurol. 2014;75(3):411-28. https://doi.org/10.1 002/ana.24117.

5. Dalmau J, Armangué T, Planagumà J, Radosevic M, Mannara F, Leypoldt F, et al. An update on anti-NMDA receptor encephalitis for neurologists and psychiatrists: mechanisms and models. Lancet Neurol. 2019;18(11):1045-57. https://doi.org/10.1016/S1474-4422(19)30244-3.

6. Nasreddine ZS, Phillips NA, Bédirian V, Charbonneau S, Whitehead V, Collin I, et al. The Montreal cognitive assessment, MoCA: a brief screening tool for mild cognitive impairment. J Am Geriatr Soc. 2005;53(4):695-9. https://doi. org/10.1111/j.1532-5415.2005.53221.x.

7. Al-Diwani A, Handel A, Townsend L, Pollak T, Leite MI, Harrison PJ, et al. The psychopathology of NMDAR-antibody encephalitis in adults: a systematic review and phenotypic analysis of individual patient data. Lancet Psychiatry. 2019:6(3):235-46. https://doi.org/10.1016/S2215-0366(19)30001-X.

8. Pollak TA, Lennox BR, Müller S, Benros ME, Prüss H, van Tebartz EL, et al. Autoimmune psychosis: an international consensus on an approach to the diagnosis and management of psychosis of suspected autoimmune origin. Lancet Psychiatry. 2020;7(1):93-108. https:/doi.org/10.1016/52215-0366(19)30290-1.

9. Wingerchuk DM, Banwell B, Bennett JL, Cabre P, Carroll W, Chitnis T, et al. International consensus diagnostic criteria for neuromyelitis optica spectrum disorders. Neurology. 2015;85(2):177-89. https://doi.org/10.1212/WNL. 0000000000001729 .

10. Kataoka H, Dalmau J, Ueno S. Paraneoplastic encephalitis associated with ovarian teratoma and $\mathrm{N}$-methyl-D-aspartate receptor antibodies. Eur J Neurol. 2008;15(0):e5-6. https://doi.org/10.1111/j.1468-1331.2007.02005.x.

11. Graus F, Titulaer MJ, Balu R, Benseler S, Bien CG, Cellucci T, et al. A clinical approach to diagnosis of autoimmune encephalitis. Lancet Neurol. 2016; 15(4):391-404. https://doi.org/10.1016/S1474-4422(15)00401-9.

12. Herken J, Prüss $\mathrm{H}$. Red flags: clinical signs for identifying autoimmune encephalitis in psychiatric patients. Front Psychiatry. 2017:8:25. https://doi. org/10.3389/fpsyt.2017.00025.

13. Endres D, Bechter K, Prüss H, Hasan A, Steiner J, Leypoldt F, et al. Autoantikörper-assoziierte schizophreniforme Psychosen: klinische Symptomatik. Nervenarzt. 2019;90(5):547-63. https://doi.org/10.1007/s00115019-0700-z.

14. Najjar S, Steiner J, Najjar A, Bechter K. A clinical approach to new-onset psychosis associated with immune dysregulation: the concept of autoimmune psychosis. J Neuroinflammation. 2018;15(1):40. https://doi. org/10.1186/s12974-018-1067-y.

15. Steiner J, Prüß H, Köhler S, Hasan A, Falkai P. Autoimmunenzephalitis mit psychotischer Symptomatik : Diagnostik, Warnhinweise und praktisches Vorgehen. Nervenarzt. 2018;89(5):530-8. https://doi.org/10.1007/s00115-0180499-z.

16. van Tebartz EL, Bechter K, Prüss H, Hasan A, Steiner JH, Leypoldt F, et al. Autoantikörper-assoziierte schizophreniforme Psychosen: Pathophysiologie. Diagn Ther Nerv. 2019;90(7):745-61. https://doi.org/10.1007/s00115-019-0735-1.

17. Pérez CA, Agyei P, Gogia B, Harrison R, Samudralwar R. Overlapping autoimmune syndrome: a case of concomitant anti-NMDAR encephalitis and myelin oligodendrocyte glycoprotein (MOG) antibody disease. J Neuroimmunol. 2020;339:577124. https://doi.org/10.1016/j.jneuroim.2019. 577124.

18. Jarius S, Paul F, Aktas O, Asgari N, Dale RC, de Seze J, et al. MOG encephalomyelitis: international recommendations on diagnosis and antibody testing. J Neuroinflammation. 2018;15(1):134. https://doi.org/10.11 86/s12974-018-1144-2.

19. Wynford-Thomas R, Jacob A, Tomassini V. Neurological update: MOG antibody disease. J Neurol. 2019;266(5):1280-6. https://doi.org/10.1007/ s00415-018-9122-2.

20. Baheerathan A, Brownlee WJ, Chard DT, Shields K, Gregory R, Trip SA. Antecedent anti-NMDA receptor encephalitis in two patients with multiple sclerosis. Mult Scler Relat Disord. 2017;12:20-2. https://doi.org/10.1016/..msa rd.2016.12.009

21. Gulec B, Kurucu H, Bozbay S, Dikmen Y, Sayman H, Tuzun E, et al. Coexistence of multiple sclerosis and anti-NMDA receptor encephalitis: a case report and review of literature. Mult Scler Relat Disord. 2020;42:102075. https://doi.org/10.1016/j.msard.2020.102075.

22. Prüß H, Köhler S, Müller S. Autoimmune Enzephalitiden - diagnostischer und therapeutischer Entscheidungsbaum aus psychiatrischer, neurologischer und ethisch-juristischer Sicht : Vorgehensweise bei fehlender Einwilligungsfähigkeit und Zulässigkeit von Zwangsbehandlungen. Nervenarzt. 2020;91(2):122-30. https://doi.org/10.1007/s00115-019-00802-1.

23. Titulaer MJ, McCracken L, Gabilondo I, Armangué T, Glaser C, lizuka T, et al. Treatment and prognostic factors for long-term outcome in patients with anti-NMDA receptor encephalitis: an observational cohort study. Lancet Neurol. 2013;12(2):157-65. https://doi.org/10.1016/S1474-4422(12)70310-1.

24. Dale RC, Brilot F, Duffy LV, Twilt M, Waldman AT, Narula S, et al. Utility and safety of rituximab in pediatric autoimmune and inflammatory CNS disease. Neurology. 2014;83(2):142-50. https://doi.org/10.1212/WNL. 0000000000000570

25. Rummel-Kluge C, Schuster T, Peters S, Kissling W. Partial compliance with antipsychotic medication is common in patients with schizophrenia. Aust N Z J Psychiatry. 2008;42(5):382-8. https://doi.org/10.1080/00048670801961107.

\section{Publisher's Note}

Springer Nature remains neutral with regard to jurisdictional claims in published maps and institutional affiliations.
Ready to submit your research? Choose BMC and benefit from:
- fast, convenient online submission
- thorough peer review by experienced researchers in your field
- rapid publication on acceptance
- support for research data, including large and complex data types
- gold Open Access which fosters wider collaboration and increased citations
- maximum visibility for your research: over $100 \mathrm{M}$ website views per year
At BMC, research is always in progress.
Learn more biomedcentral.com/submissions 